\title{
Resilience, child emotional and behavioural difficulties and stigma in mothers of children with IDD.
}

\begin{abstract}
\section{Background}

Mothers of children with intellectual and developmental disabilities (IDD) experience frequent and high levels of stigma from family, friends and members of the public. This stigma can have a negative impact on mothers' psychological well-being, their social circle and their relationship with their child.
\end{abstract}

\section{Aims}

The present study aimed to establish if there was a relationship between emotional and behavioural difficulties and stigma, and if resilience, social support and parental adjustment acted as a protective factors in this relationship.

\section{Methods}

108 mothers of children aged between four and 16 years old with IDD participated in a crosssectional online survey. Mothers were asked about their child's behavioural difficulties, their experience of stigma, in addition to completing assessments of resilience, social support and parental adjustment.

\section{Results}

Overall child behavioural and emotional difficulties, and the sub domain emotional problems, hyperactivity, and low prosocial behaviour were found to be a significant independent predictors of stigma. Resilience was associated with stigma and moderated the relationship between low prosocial behaviour and stigma. There was no evidence that social support or 
parental attachment acted as protective factors in the relationship between child behavioural difficulties and stigma.

\section{Conclusions}

The results of the present study extend the findings of previous research by providing evidence that families of children with a range of developmental disabilities experience stigma, in particular when children show high levels of emotional problems and hyperactivity and low levels of prosocial behaviour. The present study also provides evidence that resilience is associated with stigma and resilience-building interventions may be beneficial to reduce the negative impact of stigma.

\section{What this paper adds?}

This paper extends the findings of previous research by establishing a relationship between child behavioural and emotional difficulties and stigma. Specifically, the presence of low prosocial behaviour and high hyperactivity and emotional difficulties. Resilience has been demonstrated to be associated with stigma when behavioural difficulties are present. This study suggests further interventional consideration for resilience-building to address stigma in this population may be beneficial.

Keywords: Resilience, protective factors, behaviour, stigma, intellectual and developmental disabilities.

Acknowledgements: The authors would like to thank the families involved in this study.

Funding Sources: This research did not receive any specific grant from funding agencies in the public, commercial, or not-for-profit sectors.

Declarations of interest: none 


\section{Introduction}

Stigma can be conceptualised as a mark of disgrace associated with a particular attribute that does not meet society's standards of normal (Goffman, 1963). It is well known that individuals diagnosed with developmental disabilities frequently encounter stigma and barriers that affect their everyday lives (Ali, Hassiotis, Strydom \& King, 2012). However, stigma and discrimination can also be aimed at the families and relatives of individuals with IDD (Green, 2003).

Stigma towards parents of children with developmental disabilities manifests itself in many forms, such as negative labelling, rude comments, being blamed for their child's condition and rejection (Ali et al., 2012; Francis, 2012). The experience of stigma is common amongst parents of children with IDD, however little research has been conducted to explore the impact of stigma on the family. Two studies conducted by Nurullah (2013) and KoroLjungberg and Bussing (2009) found, through the use of interviews and focus groups, that the experience of stigma was prevalent for both mothers and fathers of children with IDD. For instance, parents in the study conducted by Nurullah (2013) stated that members of the public had blamed them for their child's behaviour, whilst mothers interviewed by Koro-Ljungberg and Bussing (2009) explained they had chosen to avoid public places after experiencing stigma whilst out with their child. Parents in Nurullah's (2013) study also described that not only did they experience stigma when out in public with their child, they also felt that healthcare professionals and family members displayed stigma towards their child, especially within ethnic minority cultures. The experience of any form of stigma can have a profound effect on a parent's quality of life in many domains, in particular literature has suggested that stigma impacts the wellbeing of parents with a child diagnosed with IDD, as they may experience feelings of shame, embarrassment and isolation (Duran \& Ergün, 2018; Werner \& Shulman, 2015; Green, 2003), as well as affecting their ability to leave their house (Ali et al., 
2012). However, the experience of stigma is not universal for all parents of children with IDD (Werner \& Shulman, 2015). Mickelson (2001) illustrated that even though every parent in the study had a child with a developmental disability, only $4.6 \%$ of parents reported a high amount of perceived stigma, whilst $29.4 \%$ of parents felt they experienced low levels of stigma.

It is well established that mothers of children with developmental disabilities have lower levels of psychological well-being compared to mothers of typically developing children. In particular, they exhibit greater levels of depression, stress, failure and guilt (Ekas, Lickenbrock \& Whitman, 2010; Dervishaliaj, 2013). Several factors related to developmental disabilities, such as the initial diagnosis, caring for their child, their child's behaviour and financial difficulties, have already been established as having a negative impact on psychological well-being (Gupta \& Singhal, 2004; Dabrowska \& Pisula, 2010). In addition, the stigma and negative reactions that parents receive from other individuals can act as a risk factor for decreased psychological well-being in parents (Gupta \& Singhal, 2004). For example, Banga and Ghosh (2017) found that mothers of children with developmental disabilities who experienced high levels of stigma had low levels of psychological wellbeing. When parents are constantly exposed to stigma by members of the public or their family and friends, they may start to internalize that stigma which can cause elevated levels of stress and depression (Mak \& Kwok, 2010). This was demonstrated by Shin et al., (2006) who found that both mothers and fathers of children with developmental disabilities displayed increased levels of stress when they experienced high levels of stigma.

\section{The Relationship between Stigma and Behavioural Difficulties}

Children diagnosed with any developmental disability can display a range of behavioural, emotional and communication difficulties (Dabrowska \& Pisula, 2010). Parents 
may experience staring and negative comments when their child displays behaviour difficulties in public (Broady, Stoyles \& Morse, 2017). Child behavioural difficulties as a risk factor for stigma was demonstrated in Gray's (2002) study who illustrated that parents of aggressive children experienced more stigma than parents of children who did not show these behavioural difficulties. Studies conducted with parents of children with ADHD and Autism Spectrum Disorder (ASD) have illustrated that many parents frequently experience negative comments from members of the public about their parenting and behaviour management skills, because of their child's behaviour (Broady et al., 2017; Peters \& Jackson, 2009).

The visibility of a child's diagnosis can also impact the level of stigma parents experience as a result of their child's behaviour. For example, Werner and Shulman (2015) found that parents of children with ASD experienced more stigma than parents of children with physical or intellectual disabilities. Parents of children diagnosed with ASD are likely to experience higher levels of stigma when their child has no physically visible disabilities, because members of the public expect children who do not have any obvious disabilities and no differences in physical appearance to their typically developing peers, to behave the same as a typically developing child would (Gill \& Liamputtong, 2011; Francis, 2012). In line with the idea of increased public tolerance for children with easily discernible disabilities, Francis (2012) demonstrated that parents were blamed less often for their child's behaviour when the child had a visible condition, such as cerebral palsy.

\section{The Influence of Stigma on Parental Adjustment}

Considering the challenges and demands that come with raising a child with developmental disabilities, it is not surprising that the relationship between a parent and their child can come under strain. The previous research illustrates that both the diagnosis of a developmental disability and the stigma parents are subjected to, can have a detrimental 
impact on a parent's ability to adjust to raising a child with developmental disabilities. Constant exposure to stigma about one's parenting can affect how a parent adjusts to having a child with disabilities as well as having a negative impact on one's feelings and actions towards their child (Dabrowska \& Pisula, 2010; Broady et al., 2017). For example, Mikami, Chong, Saporito and $\mathrm{Na}$ (2015) demonstrated that parents who reported experiencing more instances of stigma in turn displayed increased levels of parental negativity.

However, there are also many positive outcomes that stem from parenting a child with developmental disabilities, which help to enhance a parent's relationship with their child that can in turn act as a protective factor against stigma (Lalvani, 2015). The challenges that come with raising a child with disabilities may provide a parent with an opportunity to change their outlook on life (Myers, Mackintosh \& Goin-Kochel, 2009), as well as helping to strengthen family relationships and increase levels of patience and empathy (Lickenbrock, Ekas \& Whitman, 2011; Halstead, Ekas, Hastings \& Griffith, 2018). The benefits of raising a child with developmental disabilities were illustrated by Hastings, Allen, McDermott and Still (2002) who indicated that mothers of children with more severe disabilities experienced more of a sense of personal growth and maturity. How parents adjust to raising a child with developmental disabilities is also impacted by how much they choose to focus on the negative opinions of others (Lickenbrock et al., 2011). Myers et al., (2009) illustrated the beneficial impact of having the ability to ignore other people's negative opinions, as they demonstrated that the mothers who had the highest levels of life satisfaction were those who had learnt to disregard people's negative comments about their child and their behaviour.

\section{The Relationship between Stigma and Social Support}

Social support has many benefits for parents of children with disabilities, not only can it help to reduce both depression and parenting stress (Ekas et al., 2010), it has also been 
found act as a buffer against stigma (Ali et al., 2012). Family members, friends and the community help parents cope with the stigma they experience by providing support in the form of empathy and encouragement (Werner \& Shulman, 2013). In addition to the support received from family and friends, one major source of social support for parents of children with disabilities is other parents of children with the same disabilities. Koro-Ljungberg and Bussing (2009) found that parents gained social support and acceptance by interacting with families who also had children with ADHD. With regards to stigma, Broady et al.,. (2017) found that participating in support groups helped to buffer against the negative impact of stigma.

However, despite the support that friends and family can provide, raising a child with developmental disabilities can put a strain on a parent's social relationships. Parents of children with disabilities often state that they have very few friendships and limited time to spend doing social activities (Werner \& Shulman, 2013). Parents may also struggle to relate to their friends who do not have a child with a disability (Green, 2003). For instance, Myers et al.,. (2009) interviewed families of children with developmental disabilities and the majority of families stated that their social lives had not increased since having a child with disabilities. This lack of social relationships deprives parents of the benefits that social support can bring as low levels of social support has also been found to be related higher levels of stigma (Werner \& Shulman, 2013).

One explanation for this decrease in social support from friends and family is that parents may in fact experience stigma from their friends and families. Parents of children with developmental disabilities frequently state that interacting with friends and families becomes stressful due to their lack of understanding surrounding their child (Jones \& Passey, 2004). Broady et al., (2017) found that many parents experienced stigma in the form of family and friends questioning their parenting abilities. Parents may also experience stigma 
from their friends and family in the form of exclusion and rejection. For instance, Gray (2002) found that parents frequently found that they received less invites from friends and family to social occasions. As a result of this stigma, parents may prevent themselves from seeking social support from their family and friends (Cantwell, Muldoon \& Gallagher, 2015).

\section{The Association between Stigma and Resilience}

Parents of children with developmental disabilities experience many challenges, some of which may be child-related, such as care giving and schooling, whilst some may be related to the opinions held by society (Breitkreuz, Wunderli, Savage \& McConnell, 2014).

However, not all families become overwhelmed in the face of these difficulties. Some families develop ways to cope with the stresses and difficulties in order to maximise their well-being (Grant, Ramcharan \& Flynn, 2007). Resilience has been defined by Rutter (1987) as being "concerned with individual variations in response to risk. Some people succumb to stress and adversity whereas others overcome life hazards". One of the many triggers that many parents of children with developmental disabilities demonstrate resilience to is stigma. Past studies have found that parents show resilience in the face of stigma by trying to keep their lives as normal as possible working hard to integrate their child into the community (Breitkreuz et al., 2014). Furthermore, Grant et al., (2007) found that even though parents are aware of the stigma towards themselves and their child, they prevent it affecting them by maintaining a sense of integrity. It is important that parents of children with developmental disabilities display resilience and maximise its protective ability, as it has been shown that low levels of resilience can lead to poorer outcomes for the parents and the family as a whole. This was illustrated by Choi and Yoo (2015) who demonstrated that parents with lower levels of resilience reported higher levels of depression and stress.

\section{Aims of the Study}


The aim of the present study is to investigate whether child emotional and behavioural difficulties are associated with stigma. Further to this, the present study aims to investigate whether resilience, parental adjustment, and social support act as protective factors in the relationship between child emotional behavioural difficulties and stigma.

\section{Methods}

\section{Participants}

Participants were 108 mothers (104 biological, 4 adoptive) of children aged between 4 and 16 years old $(\mathrm{M}=10.15, \mathrm{SD}=3.31)$ with IDD. The participants were 103 primary carers and five secondary carers, with primary caregivers having main caregiving responsibility for their child. Only 8 fathers fully completed the survey. Previous research has demonstrated differences in experiences between mothers and fathers (Hartley et al., 2011), as the fathers sample was deemed too small for separate analysis, fathers were excluded.

The gender of the participants' children was $80 \mathrm{~m}, 26 \mathrm{f}$, one other, whilst one parent did not disclose. The children had a variety of primary diagnoses of IDD, $73.1 \%$ were diagnosed with Autism Spectrum Disorders, 10.2\% with Down's syndrome, $4.6 \%$ with Global Developmental Delay, 2.8\% with Learning Disability and 9.3\% with other diagnoses such as Cerebral Palsy and Fragile X Syndrome. Mean stigma scores for each diagnosis are presented in Table 1.

Table 1.

Mean stigma scores for child diagnosis.

\begin{tabular}{llllll}
\hline & $\begin{array}{l}\text { Autism } \\
\text { Spectrum } \\
\text { Disorder }\end{array}$ & $\begin{array}{l}\text { Down's } \\
\text { Syndrome }\end{array}$ & $\begin{array}{l}\text { Global } \\
\text { Developmental } \\
\text { Delay }\end{array}$ & $\begin{array}{l}\text { Learning } \\
\text { Disability }\end{array}$ & Other \\
\hline Stigma & 79.88 & 73.7 & 72.4 & 77.87 & 82.48 \\
\hline
\end{tabular}




\section{Procedure}

The study was as an online survey using the data collection web application, REDCAP. The study received approval from an UK institutional research ethics review board. Participants were recruited using a multi-level approach. The link to the survey was distributed on flyers via social media and also through support groups for parents of children with developmental disabilities. To be eligible to participate in the study, participants had to be the primary or secondary carer of a child, aged between $4-16$ years old, with a developmental disability. Participants were required to answer the consent questions before they could proceed with the survey. Participants were then required to complete seven demographic questions as well as six questionnaires.

\section{Measures}

Participants were required to answer three demographic questions about themselves; their gender, their relationship to their child, and whether they were their child's primary or secondary carer. Participants were then required to answer four demographic questions about their child; their child's gender, age and their child's primary and secondary diagnoses. After answering the demographic questions participants then completed the six following measures. The following measures have all demonstrated in previous studies good internal consistency in parents/carers of children with IDD populations. Specifically, the Family Stigma Instrument and the Positive Gain Scale were developed for this population.

Stigma: The Family Stigma Instrument (FAMSI: Mitter, Ali \& Scior, 2018) is a 26item questionnaire assessing the levels of stigma faced by family members of individuals with intellectual disabilities. Participants answer each item using a five-point likert scale scoring from 1 (strongly disagree) to 5 (strongly agree). A participants' total score can range from 28 to 140, with higher scores indicating that individuals have experienced a higher level 
of stigma. Mitter et al., (2018) demonstrated good internal consistency and moderate reliability in a sample of family carers of individuals with IDD. The internal alpha coefficient in the present study was .779.

Child emotional and behavioural difficulties: The strengths and difficulties questionnaire (SDQ: Goodman, 1997) is a 25-item scale that asks parents about their child's behaviour over the past six months. Parents are provided with 25 statements about behaviour and are asked to decide whether the statement is not true, somewhat true, or certainly true about their child. 20 of the items in the questionnaire are scored from 0 (not true) to 2 (certainly true). The other five items are reversed scored. There are 5 sub domains; hyperactivity, prosocial behaviour, emotional problems, conduct problems, and peer problems. A total difficulties score is comprised of the total scores from the emotional, conduct and peer problems scales as well as the hyperactivity scale. The total score can range from zero to 40. In these four sub domains, and thus the total score, a higher score indicates more emotional and behavioural difficulties. With regards to the prosocial scale, a higher score represents more prosocial behaviour. The SDQ is a well validated instrument and research with children with IDD and their parents, previous studies have demonstrated good levels of reliability (Beck et al., 2004; Hastings et al., 2006). The internal alpha coefficient in the present study for total difficulties was .710.

Resilience: The brief resilient coping scale (Sinclair \& Wallston, 2004) is a four-item questionnaire assessing an individual's levels of resilience. Each item is answered on a five point likert scale ranging from 1 (does not describe me at all) to 5 (describes me very well). Once a total score is obtained, individuals with scores in the range of 4-13 points are described as low resilient copers, those with 14-16 points are described as medium resilient copers and those with a score in the range of 17-20 are described as high resilient copers. 
Previously, this measure has demonstrated good reliability in parents/carers of children with IDD (Halstead et al., 2018). The internal alpha coefficient in the present study was .690.

Social Support: The multidimensional scale of perceived social support (Zimet et al., 1988) contains twelve items assessing the levels of support an individual receives from their family, friends and significant other. The questions are answered on a seven-point likert scale from 1 (very strongly disagree) to 7 (very strongly agree). Higher total scores are indicative of higher levels of social support. Previous studies have demonstrated good reliability for parents/carers of children with IDD (e.g. Heiman \& Berger, 2007). The internal alpha coefficient in the present study was .941 .

Parental adjustment: The positive gain scale (PGS: Pit-ten Cate, 2003) is a sevenitem questionnaire assessing parents' attachment and adjustment to their children with disabilities. All seven questions are answered on a five-point likert scale with answers from 1 (strongly agree) to 5 (strongly disagree). The total score can range from seven to 35 with lower scores indicating higher levels of adjustment. High internal consistency has previously been demonstrated with parents of children with IDD (Jones et al., 2014). The internal alpha coefficient for the positive gain scale in the present study was .797.

\section{Missing Data}

Where there was missing data, an average score for that question was calculated based on the mean of the total score for that particular subscale or measure (Kang, 2013). During this process, one participant was removed from the analysis because two of their subscales on the strengths and difficulties questionnaire (Goodman, 1997) were too incomplete for averaging. Once all missing data was accounted for, then the data was analysed using IBM SPSS Statistics (IBM Corp., 2017).

\section{Results}


To assess social support, resilience, and parental attachment as potential protective factors in the relationship between child behavioural and emotional difficulties and stigma 6 multiple regression analyses were conducted for each protective factor. Demographic variables were selected to be included in each analysis from bivariate analysis (correlations or $t$-tests). Spearman's correlations found mothers who reported higher levels of stigma also reported higher overall child behavioural and emotional difficulties $(p<.01)$, emotional problems $(p<$ $.05)$, hyperactivity $(p<.05)$, and peer problems $(p<.05)$, along with lower prosocial behaviour $(p<.05)$. There was no significant correlation between conduct problems and stigma $(p=.06)$. Further correlations and $t$-tests found no significant results between stigma and diagnosis (Autism $(p=.223)$, Down's Syndrome $(p=.089))$, child age $(p=.186)$ or child's gender $(p=.967)$.

Six predictor variables were entered separately for each analysis for the 3 protective factors (social support, resilience, and parental attachment). These included; overall behavioural and emotional problems and the 5 sub domains; emotional problems, hyperactivity, prosocial behavioural, conduct problems and peer problems). Resilience, social support, and parental adjustment were entered as a main effect variable, and as an interaction variable with child behavioural and emotional problems. The 'PROCESS' custom dialog box (Hayes 2012) installed into SPSS analytics software for the moderated multiple regression analysis. Multicollinearity issues between variables were checked using the Variance Inflation Factor (VIF) and the variables showed no multicollinearity problems (all values < 10 , average $>1$, tolerance $>0.1$; Bowerman \& O’Connell, 1990; Myers, 1990). Both the predictor and moderator variables were mean-centered (the variable mean is subtracted from very value of the variable). Mean and range values for each measure are presented in Table 2.

\section{Table 2.}


Maternal mean and range values for each measure.

\begin{tabular}{|c|c|c|c|}
\hline & & Mean & Range \\
\hline Resilience & & 15.38 & 11 \\
\hline Stigma & & 79.09 & 56 \\
\hline Social Support & & 57.89 & 72 \\
\hline Parental & & 28.71 & 20 \\
\hline Adjustment & & & \\
\hline Total Emotional & & 19.84 & 28.5 \\
\hline & Prosocial behaviour & 4.93 & 10 \\
\hline & Emotional Problems & 5.33 & 10 \\
\hline & Conduct Problems & 3.4 & 8 \\
\hline & Hyperactivity & 5.23 & 9 \\
\hline & Peer Problems & 5.88 & 8 \\
\hline & & 28.71 & 20 \\
\hline
\end{tabular}

The moderated multiple regression analysis showed that overall child behavioural and emotional difficulties and the sub domain emotional problems each had a significant association with stigma in all models ( $p$ s <.05) (see Tables 3 and 4). In addition, hyperactivity and prosocial behaviour sub domains were found to be significantly associated with stigma in some models. Specifically, hyperactivity was associated with stigma in parental adjustment $(p=.003)$ and social support models $(p=.03)$ and prosocial behaviour was associated with stigma in the social support and resilience models $(\mathrm{ps}=.04)$. Parental adjustment and social support were not found to be associated with stigma or interact with child behavioural and emotional difficulties.

Conduct problems $(p=.056)$ and resilience $(p=.007)$ each had significant or close to significant associations with stigma. Prosocial behaviour and resilience $(p=.01)$ each had a significant association with stigma. In this model, there was a significant interaction term, suggesting that these main effects could be interpreted in relation to an interaction effect. Following the recommendation by Aiken and West (1991), a simple slope analysis was 
conducted to aid interpretation of this interaction (see Figure 1). There was a negative relationship (as prosocial behaviour increased, stigma decreased) between prosocial behaviour and stigma when resilience was low $\mathrm{b}=-1.88,95 \%$ CI $[-3.01,-.75], \mathrm{t}=-3.29, \mathrm{p}<$ .01 and when resilience was average $\mathrm{b}=-.81,95 \%$ CI $[-1.57,-.05], \mathrm{t}=-2.11, \mathrm{p}<.05$. When was resilience was high there was a non-significant positive relationship between prosocial behaviour and stigma, $\mathrm{b}=.25,95 \% \mathrm{CI}[-.83,1.33], \mathrm{t}=.46, \mathrm{p}=.64$. Visual inspection of the slopes showed that lower or average levels of resilience were associated with lower stigma when prosocial behaviour were at high levels.

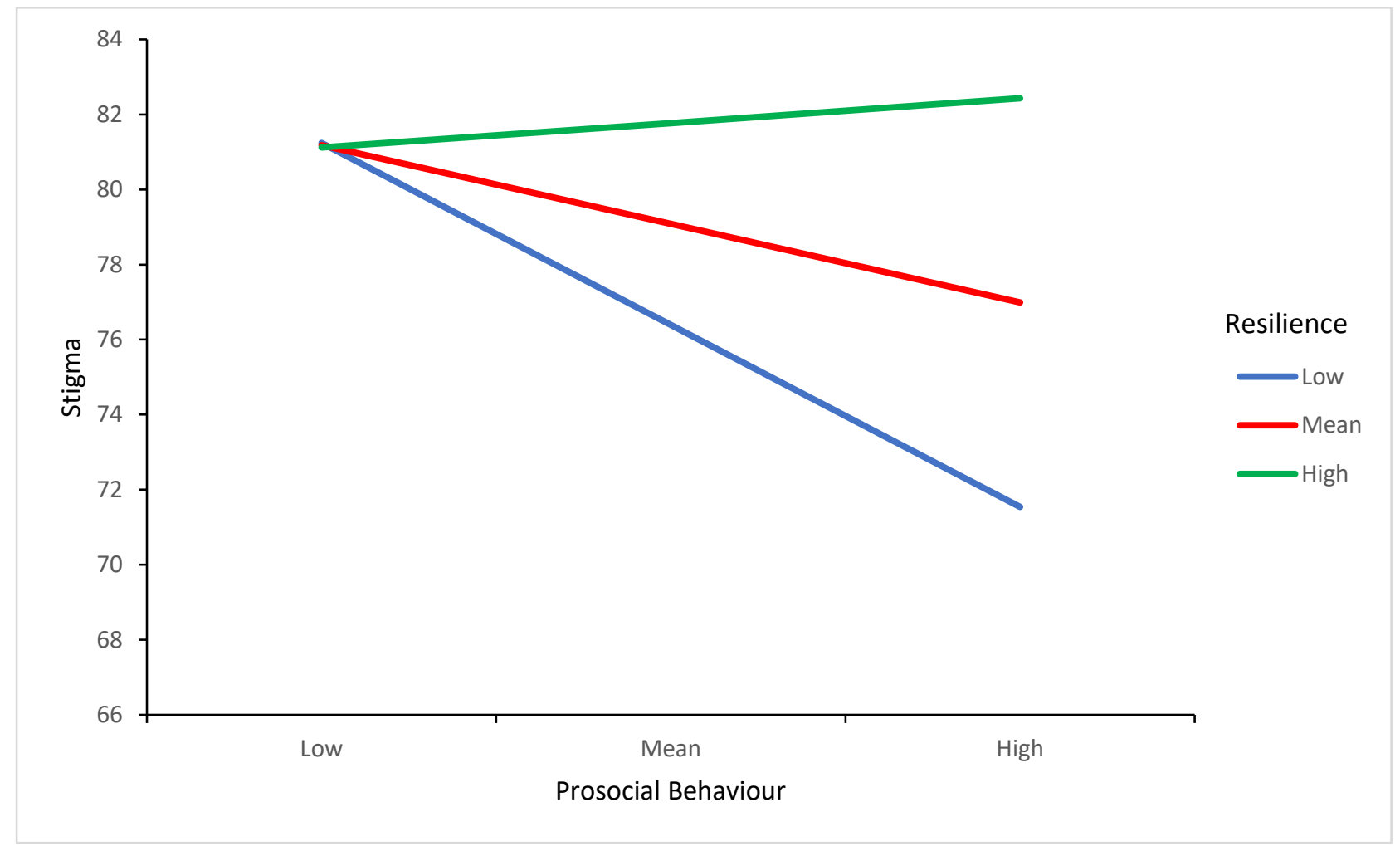

Figure 1. Simple slope graph for stigma experienced by mothers of having a child with IDD as the outcome variable. There was a negative relationship between prosocial behaviour and stigma at low $(p<.01)$ and mean $(p<.05)$ levels of resilience, but not when resilience was high $(p=.64)$. 

Table 3.

Moderated Multiple Regression Analysis Models for child Total Emotional and Behavioural Difficulties as a predictor variable.

\begin{tabular}{|c|c|c|c|c|c|c|c|c|c|c|c|}
\hline \multicolumn{4}{|c|}{$\mathrm{R}=.324, \mathrm{R}^{2}=.105, \mathrm{~F}=4.99, \mathrm{p}<.01$} & \multicolumn{4}{|c|}{$R=.279, R^{2}=.078, F=3.748, p=.01$} & \multicolumn{4}{|c|}{$\mathrm{R}=.296, \mathrm{R}^{2}=.088, \mathrm{~F}=3.803, \mathrm{p}=.01$} \\
\hline & $\mathrm{b}$ & $\mathrm{t}$ & $P$ & & $\mathrm{~b}$ & $\mathrm{~T}$ & $p$ & & $\mathrm{~b}$ & $\mathrm{t}$ & $p$ \\
\hline $\begin{array}{l}\text { Total Emotional and } \\
\text { Behavioural } \\
\text { Difficulties }\end{array}$ & .44 & 2.65 & .009 & $\begin{array}{l}\text { Total Emotional and } \\
\text { Behavioural Difficulties }\end{array}$ & .51 & 2.96 & .003 & $\begin{array}{l}\text { Total Emotional and } \\
\text { Behavioural } \\
\text { Difficulties }\end{array}$ & .51 & 3.3 & .001 \\
\hline Resilience & .64 & 1.43 & .15 & Social Support & .05 & .70 & .49 & Parental Adjustment & .27 & 1.04 & .3 \\
\hline $\begin{array}{l}\text { Total Emotional and } \\
\text { Behavioural } \\
\text { Difficulties x } \\
\text { Resilience }\end{array}$ & $\begin{array}{l}- \\
.04\end{array}$ & -.65 & .52 & $\begin{array}{l}\text { Total Emotional and } \\
\text { Behavioural Difficulties } \\
\text { x Social Support }\end{array}$ & -.002 & -.20 & .84 & $\begin{array}{l}\text { Total Emotional and } \\
\text { Behavioural } \\
\text { Difficulties x Parental } \\
\text { Adjustment }\end{array}$ & $\begin{array}{l}- \\
.02\end{array}$ & -.72 & .47 \\
\hline
\end{tabular}


Table 4.

Moderated Multiple Regression Analysis Models for child Emotional and Behavioural Difficulties sub domains as predictor variables.

\begin{tabular}{|c|c|c|c|c|c|c|c|c|c|c|c|}
\hline \multicolumn{4}{|c|}{$R=.311, R^{2}=.097, F=3.67, p=.01$} & \multicolumn{4}{|c|}{$R=.243, R^{2}=.059, F=2.072, p=.109$} & \multicolumn{4}{|c|}{$\mathrm{R}=.253, \mathrm{R}^{2}=.064, \mathrm{~F}=2.157, \mathrm{p}=.098$} \\
\hline & $\mathrm{b}$ & $\mathrm{t}$ & $P$ & & $\mathrm{~b}$ & $\mathrm{~T}$ & $p$ & & $\mathrm{~b}$ & $\mathrm{t}$ & $p$ \\
\hline $\begin{array}{l}\text { Emotional } \\
\text { Problems x } \\
\text { Resilience }\end{array}$ & -.16 & -1.48 & .14 & $\begin{array}{l}\text { Emotional } \\
\text { Problems x } \\
\text { Social Support }\end{array}$ & -.02 & -1.00 & .34 & $\begin{array}{l}\text { Emotional } \\
\text { Problems x } \\
\text { Parental } \\
\text { Attachment }\end{array}$ & -.05 & -.78 & .44 \\
\hline \multicolumn{4}{|c|}{$\mathrm{R}=.316, \mathrm{R}^{2}=.1, \mathrm{~F}=4.94, \mathrm{p}=.003$} & \multicolumn{4}{|c|}{$\mathrm{R}=.184, \mathrm{R}^{2}=.034, \mathrm{~F}=1.2, \mathrm{p}=.314$} & \multicolumn{4}{|c|}{$\mathrm{R}=.211, \mathrm{R}^{2}=.045, \mathrm{~F}=1.209, \mathrm{p}=.31$} \\
\hline & $\mathrm{b}$ & $\mathrm{t}$ & $P$ & & $\mathrm{~b}$ & $\mathrm{~T}$ & $p$ & & $\mathrm{~b}$ & $\mathrm{t}$ & $p$ \\
\hline $\begin{array}{l}\text { Conduct } \\
\text { Problems }\end{array}$ & 1.30 & 1.93 & .056 & $\begin{array}{l}\text { Conduct } \\
\text { Problems }\end{array}$ & 1.18 & 1.57 & .12 & $\begin{array}{l}\text { Conduct } \\
\text { Problems }\end{array}$ & 1.20 & 1.59 & .12 \\
\hline Resilience & 1.01 & 2.75 & .007 & Social Support & .03 & .38 & .71 & $\begin{array}{l}\text { Parental } \\
\text { Attachment }\end{array}$ & .27 & .94 & .35 \\
\hline
\end{tabular}




\begin{tabular}{|c|c|c|c|c|c|c|c|c|c|c|c|}
\hline & $\mathrm{b}$ & $\mathrm{t}$ & $P$ & & $\mathrm{~b}$ & $\mathrm{~T}$ & $p$ & & $\mathrm{~b}$ & $\mathrm{t}$ & $p$ \\
\hline Hyperactivity & 1.01 & 1.82 & .07 & Hyperactivity & 1.47 & 2.16 & .03 & Hyperactivity & 1.52 & 2.99 & .003 \\
\hline Resilience & .60 & 1.40 & .17 & Social Support & .05 & .69 & .49 & $\begin{array}{l}\text { Parental } \\
\text { Attachment }\end{array}$ & .31 & 1.20 & .23 \\
\hline $\begin{array}{l}\text { Hyperactivity } \\
\text { x Resilience }\end{array}$ & -.09 & -.55 & .58 & $\begin{array}{l}\text { Hyperactivity } \\
\text { x Social } \\
\text { Support }\end{array}$ & -.01 & -.10 & .92 & $\begin{array}{l}\text { Hyperactivity } \\
\text { x Parental } \\
\text { Attachment }\end{array}$ & -.08 & -.72 & .47 \\
\hline \multicolumn{4}{|c|}{$\mathrm{R}=.26, \mathrm{R}^{2}=.068, \mathrm{~F}=2.491, \mathrm{p}=.064$} & \multicolumn{4}{|c|}{$\mathrm{R}=.183, \mathrm{R}^{2}=.034, \mathrm{~F}=1.582, \mathrm{p}=.198$} & \multicolumn{4}{|c|}{$\mathrm{R}=.182, \mathrm{R}^{2}=.033, \mathrm{~F}=1.273, \mathrm{p}=.288$} \\
\hline & $\mathrm{b}$ & $\mathrm{t}$ & $P$ & & $\mathrm{~b}$ & $\mathrm{~T}$ & $p$ & & $\mathrm{~b}$ & $\mathrm{t}$ & $p$ \\
\hline Peer Problems & .96 & 1.27 & .21 & Peer Problems & 1.03 & 1.29 & .20 & Peer Problems & .99 & 1.39 & .17 \\
\hline Resilience & .73 & 1.42 & .16 & Social Support & .02 & .19 & .85 & $\begin{array}{l}\text { Parental } \\
\text { Attachment }\end{array}$ & .19 & .57 & .57 \\
\hline $\begin{array}{l}\text { Peer Problems } \\
\text { x Resilience }\end{array}$ & .16 & .49 & .62 & $\begin{array}{l}\text { Peer Problems } \\
\text { x Social } \\
\text { Support }\end{array}$ & .02 & .38 & .71 & $\begin{array}{l}\text { Peer Problems } \\
\text { x Parental } \\
\text { Attachment }\end{array}$ & .02 & .09 & .92 \\
\hline \multicolumn{4}{|c|}{$\mathrm{R}=.38, \mathrm{R}^{2}=.144, \mathrm{~F}=4.848, \mathrm{p}<.01$} & \multicolumn{4}{|c|}{$\mathrm{R}=.233, \mathrm{R}^{2}=.054, \mathrm{~F}=2.021, \mathrm{p}=.116$} & \multicolumn{4}{|c|}{$\mathrm{R}=.234, \mathrm{R}^{2}=.055, \mathrm{~F}=1.204, \mathrm{p}=.312$} \\
\hline & $\mathrm{b}$ & $\mathrm{t}$ & $P$ & & $\mathrm{~b}$ & $\mathrm{~T}$ & $p$ & & $\mathrm{~b}$ & $\mathrm{t}$ & $p$ \\
\hline $\begin{array}{l}\text { Prosocial } \\
\text { Behaviour }\end{array}$ & -.81 & -2.11 & .04 & $\begin{array}{l}\text { Prosocial } \\
\text { Behaviour }\end{array}$ & -.88 & -2.11 & .04 & $\begin{array}{l}\text { Prosocial } \\
\text { Behaviour }\end{array}$ & -.89 & 1.90 & .06 \\
\hline Resilience & .94 & 2.59 & .01 & Social Support & .0002 & .003 & .10 & $\begin{array}{l}\text { Parental } \\
\text { Attachment }\end{array}$ & .25 & .85 & .40 \\
\hline $\begin{array}{l}\text { Prosocial } \\
\text { Behaviour x } \\
\text { Resilience }\end{array}$ & .37 & 2.63 & .01 & $\begin{array}{l}\text { Prosocial } \\
\text { Behaviour x } \\
\text { Social Support }\end{array}$ & .03 & 1.25 & .21 & $\begin{array}{l}\text { Prosocial } \\
\text { Behaviour x } \\
\text { Parental } \\
\text { Attachment }\end{array}$ & .05 & .40 & .69 \\
\hline
\end{tabular}




\section{Discussion}

The results of the moderated multiple regression analysis illustrate that child behavioural and emotional difficulties are associated with stigma, specifically, emotional problems, hyperactivity, and prosocial behaviour. Our results found that when child emotional problems and hyperactivity are high, their mothers experienced higher levels of stigma. In addition, when prosocial behaviour is low, this was related to higher stigma experienced by mothers. Previous findings have also shown an overall association between child behavioural difficulties and stigma. For example Mitter et al., (2018) found challenging behaviour to predict stigma using the family stigma instrument in parents/carers of children with IDD. Furthermore, many studies, such as those conducted by Broady et al., (2017) and Peters and Jackson (2009), had established a relationship between stigma in behaviour difficulties in parents of children with ASD and ADHD. However, our findings provide further clarity in the types of child emotional and behavioural difficulties (e.g. hyperactivity, low prosocial behaviour, emotional problems) that may contribute to higher stigma for families in comparison to other types of behavioural difficulties (e.g. peer problems). These findings add support to previous research, in particular that of Gray (2002) who found that parents of children with IDD who demonstrated aggressive behaviour experienced more stigma than parents of children who did not show such extreme behaviour difficulties.

In our study, social support and parental adjustment were not significantly associated with stigma, and did not act as protective factors between child behavioural and emotional difficulties and stigma. Similarly, Mitter, Ali and Scior (2018), did not find social support to be a significant predictor of stigma when using both the MSSS to measure social support and the FAMSI to measure stigma, both measures were also used in this study. Previously, studies have found the role of social support and parental adjustment as potential moderating factors that, when present, buffer the impact of a stressor (such as stigma) to improve mental 
health and well-being outcomes. Social support has been found to buffer the impact of stigma for parents of children with IDD, leading to better mental health outcomes (Broady et al., 2017). In addition, social support has found to moderate the relationship between child behavioural and emotional problems and maternal well-being in mothers of children with IDD (Halstead et al., 2017). Parental adjustment has also previously been conceptualised as a potential moderating variable which may impact the relationship between stigma and the effect on parental mental health (Papadopoulos et al., 2018). Therefore, social support and parental adjustment are likely to act as moderating variables that buffer against the negative impact of stigma, such as mental health and well-being, in this population (Werner \& Shulman, 2013).

Our study found that resilience moderated the relationship between prosocial behaviour and stigma. Overall, more stigma was reported when prosocial behaviour was lower. However, visual inspection of the findings suggested that if prosocial behaviour was high, mothers reported lower stigma when their resilience was low or average compared to when their resilience was high. This finding does not suggest that higher resilience buffers the relationship between low prosocial behaviour and higher stigma, therefore, resilience is not acting as a protective factor. However, this finding may be because our study focused on child behavioural and emotional difficulties and the relationship with stigma, in a wider context resilience may buffer the negative effects of stigma on mental health in mothers, as demonstrated in previous research (e.g. Halstead et al., 2018).

Previous research that has found parents demonstrate resilience in the face of stigma by maintaining normal lives and a sense of integrity (Breitkreuz et al., 2014; Grant et al., 2007). We found that resilience is associated to stigma, and this suggests that more could be done to foster family resilience in order to help them cope with the stigma and stress they experience. Previous research has stated that by supporting parents to enhance factors that 
contribute to the development of resilience, clinicians may be better placed to advise parents about how to handle their levels of stress (Peer \& Hillman, 2014). In a systematic review by Papadopoulos et al., (2018) several factors relating to the concept of building resilience were identified as targets for intervention to boost resilience towards stigma. These included; caregiver burden, emotional and professional support, positive meaning to caregiving, and self- esteem. One recent intervention by Park et al., (2020) delivered a virtual resiliency programme to parents of children with learning and attentional difficulties. The results were promising and demonstrated improvements in well-being, social support and empathy. The intervention targeted a number of stressors such as financial stress and interactions with other parents.

Delivery of an intervention focusing on stigma and the associated child behavioural and emotional difficulties as stressors that can increase stigma, may be beneficial to families. In most studies, resilience is an individual construct which in most studies is defined as enables the successful adaptation to stressors in the absence of psychological distress or family dysfunction. Therefore, resilience-building interventions are focused on fostering and increasing resilience in the individual, caregiver and/or family (McConnell \& Savage, 2015) However, stigma is influenced by cultural differences, and associated with mental health in families (Papadopoulos et al., 2018). Therefore, McConnell \& Savage (2015) suggested the ecocultural theory (Weisner et al. 2005) offers a conceptual approach to investigating the resilience of families of children with ID, as this approach focuses more on the availability of accessibility of culturally relevant resources than individual factors.

\section{Limitations}

Gathering of further demographic variables, such as socio-economic status could have provided further insight into the results. The present research sample may have been slightly 
biased towards participants of a higher socioeconomic status, as individuals with a lower socioeconomic status are underrepresented in research and are less likely to fully complete on online survey (Lingwood, Levy, Billington \& Rowland, 2020; Jang \& Vorderstrasse, 2019). Consideration of socioeconomic status is important as previous research has demonstrated that individuals from low socioeconomic backgrounds tend to experience more difficulties in their daily lives, such as stress and stigma, which may be amplified when having a child with IDD. Shin et al., (2006) found that fathers who had a low socioeconomic status experienced more stress than fathers who had a high socioeconomic status.

Previous research has established that mothers tend to feel more stigmatised than fathers because they are seen as the primary caregiver by members of the public (Gill \& Liamputtong, 2011). This study included mothers, therefore, future research could attempt to address fathers' perceptions of stigma that occur due to parenting a child with IDD and conduct a comparison between mothers and fathers in order to determine the differences in their perceptions of stigma as well as to compare how mothers and fathers cope with the stigma they experience.

Stigma is not a one-off occurrence and parents must deal with the negative attitudes of others for a prolonged period of time. In this study we take a cross-sectional approach, however, resilience may build over time (e.g. Andrews, Page, \& Neilson, 1993). A longitudinal study to examine how parents experience of stigma changes throughout their child's life may be beneficial in gaining further insight into the impact of stigma. In addition, this type of study would also help to highlight how any protective factors, such as resilience, develop and how parents of children with IDD learn to cope with the stigma they face over time. 
To conclude, this study offers additional insight into the relationship between child behavioural and emotional difficulties and stigma, and the role of resilience in this relationship. The impact of stigma, along with the promotion of resilience should be considered in both clinical and research practice to improve well-being in families of children with IDD when behavioural difficulties are present. 


\section{References}

Ali, A., Hassiotis, A., Strydom, A. \& King, M. (2012). Self stigma in people with intellectual disabilities and courtesy stigma in family carers: A systematic review. Research in Developmental Disabilities, 33, $2122-2140$.

Andrews, G., Page, A. C., \& Neilson, M. (1993). Sending your teenagers away: controlled stress decreases neurotic vulnerability. Archives of General Psychiatry, 50(7), 585- 589.

Banga, G. \& Ghosh, S. (2017). The impact of affiliate stigma on the psychological well-being of mothers of children with specific learning disabilities in India: The mediating role of subjective burden. Journal of Applied Research in Intellectual Disabilities, 30, 958 - 969.

Beck, A., Daley, D., Hastings, R. P., \& Stevenson, J. (2004). Mothers' expressed emotion towards children with and without intellectual disabilities. Journal of Intellectual Disability Research, 48(7), 628-638.

Bowerman, B. L., \& O'Connell, R. T. (1990). Linear statistical models: An applied approach (2nd ed.). Belmont, CA: Duxbury.

Breitkreuz, R., Wunderli, L., Savage, A. \& McConnell, D. (2014). Rethinking resilience in families of children with disabilities: a socioecological approach. Community, Work \& Family, 17 (3), $346-365$.

Broady, T. R., Stoyles, G. J. \& Morse, C. (2017). Understanding carers' lived experience of stigma: the voice of families with a child on the autism spectrum. Health and Social Care in the Community, 25 (1), $224-233$.

Cantwell, J., Muldoon, O. \& Gallagher, S. (2015). The influence of self-esteem and social support on the relationship between depressive symptomology in parents caring for children with intellectual disabilities. Journal of Intellectual Disability Research, 59 (10), 948 - 957.

Choi, E. K. \& Yoo, I. Y. (2015). Resilience in families of children with Down Syndrome in Korea. International Journal of Nursing Practice, 21, 532 - 541. 
Dabrowska, A. \& Pisula, E. (2010). Parenting stress and coping styles in mothers and fathers of preschool children with autism and Down syndrome. Journal of Intellectual Disability Research, $54(3), 266-280$.

Dervishaliaj, E. (2013). Parental stress in families of children with disabilities: A literature review. Journal of Educational and Social Research, 3 (7), 579 - 584.

Duran, S. \& Ergün, S. (2018). The stigma perceived by parents of intellectual disability children: an interpretative phenomenological analysis study. Anatolian Journal of Psychiatry, 19 (4), 390 $-396$.

Ekas, N. V., Lickenbrock, D. M. \& Whitman, T. L. (2010). Optimism, social support, and well-being in mothers of children with autism spectrum disorder. Journal of Autism and Developmental Disorders, 42, 1274 - 1284.

Francis, A. (2012). Stigma in an era of medicalisation and anxious parenting: how proximity and culpability shape middle-class parents' experiences of disgrace. Sociology of Health \& Illness, 34 (6), $927-942$.

Gill, J. \& Liamputtong, P. (2011). Being the mother of a child with Asperger's Syndrome: Women's experiences of stigma. Health Care for Women International, 32 (8), 708 - 722.

Goffman, E. (1963). Stigma: Notes on the Management of Spoiled Identity. Simon \& Schuster,

Goodman, R. (1997). The Strengths and Difficulties Questionnaire: A research note. Journal of Child Psychology and Psychiatry, 38 (5), 581-586.

Grant, G., Ramcharan, P. \& Flynn, M. (2007). Resilience in families with children and adult members with intellectual disabilities: Tracing elements of a psycho-social model. Journal of Applied Research in Intellectual Disabilities, 20, 563 - 575.

Gray, D. E. (2002). 'Everybody just freezes. Everybody is just embarrassed': felt and enacted stigma among parents of children with high functioning autism. Sociology of Health \& Illness, 24 (6), $734-749$. 
Green, S. E. (2003). "What do you mean 'what's wrong with her?"': stigma and the lives of families of children with disabilities. Social Science \& Medicine, 57, 1361 - 1374.

Gupta, A. \& Singhal, N. (2004). Positive perceptions in parents of children with disabilities. Asia Pacific Disability Rehabilitation Journal, 15 (1), 22 - 35.

Halstead, E. J., Griffith, G. M. \& Hastings, R. P. (2017). Social support, coping, and positive perceptions as potential protective factors for the well-being of mothers of children with intellectual and developmental disabilities. International Journal of Developmental Disabilities, 64 (4-5), 288 - 296.

Halstead, E., Ekas, N., Hastings, R. P. \& Griffith, G. M. (2018). Associations between resilience and the well-being of mothers of children with autism spectrum disorder and other developmental disabilities. Journal of Autism and Developmental Disorders, 48 (4), 1108 - 1121.

Hartley, S. L., Barker, E. T., Seltzer, M. M., Greenberg, J. S., \& Floyd, F. J. (2011). Marital satisfaction and parenting experiences of mothers and fathers of adolescents and adults with autism. American Journal of Intellectual and Developmental Disabilities, 116(1), 81-95.

Hastings, R. P., Allen, R., McDermott, K. \& Still, D. (2002). Factors related to positive perceptions in mothers of children with intellectual disabilities. Journal of Applied Research in Intellectual Disabilities, 15, $269-275$.

Hastings, R. P., Daley, D., Burns, C., \& Beck, A. (2006). Maternal distress and expressed emotion: Cross-sectional and longitudinal relationships with behavior problems of children with intellectual disabilities. American Journal on Mental Retardation, 111(1), 48-61.

Hayes, A. F. (2012). PROCESS: a versatile computational tool for observed variable mediation, moderation, and conditional process modelling [White paper]. http://www.afhayes.com/public/process2012.pdf 
Heiman, T., \& Berger, O. (2008). Parents of children with Asperger syndrome or with learning disabilities: Family environment and social support. Research in developmental disabilities, 29(4), 289-300.

IBM Corp. Released 2017. IBM SPSS Statistics for Windows, Version 25.0. Armonk, NY: IBM Corp.

Jang, M. \& Vorderstrasse, A. (2019). Socioeconomic status and racial or ethnic differences in participation: web-based survey. Journal of Medical Internet Research Research Protocols, 8 (4), 1 10.

Jones, J. \& Passey, J. (2004). Family adaptation, coping and resources: parents of children with developmental disabilities and behaviour problems. Journal on Developmental Disabilities, $11(1), 31-46$.

Jones, L., Hastings, R. P., Totsika, V., Keane, L., \& Rhule, N. (2014). Child behavior problems and parental well-being in families of children with autism: The mediating role of mindfulness and acceptance. American journal on intellectual and developmental disabilities, 119(2), 171185.

Kang, H. (2013). The prevention and handling of the missing data. Korean Journal of Aneshesiology, $64(5), 402-406$.

Koro-Ljungberg, M. \& Bussing, R. (2009). The management of courtesy stigma in the lives of families with teenagers with ADHD. Journal of Family Issues, 30 (9), 1175 - 1200.

Lalvani, P. (2015). Disability, stigma and otherness: Perspectives of parents and teachers. International Journal of Disability, Development and Education, 62 (4), 379 - 393.

Lickenbrock, D. M., Ekas, N. V. \& Whitman, T. L. (2011). Feeling good, feeling bad: Influences of maternal perceptions of the child and marital adjustment on well-being in mothers of children with an autism spectrum disorder. Journal of Autism and Developmental Disorders, 41, 848 858. 
Lingwood, J., Levy, R., Billington, J. \& Rowland, C. (2020). Barriers and solutions to participation in family-based education interventions. International Journal of Social Research Methodology, $23(2), 185-198$.

Mak, W. W. S. \& Kwok, Y. T. Y. (2010). Internalisation of stigma for parents of children with autism spectrum disorder in Hong Kong. Social Science \& Medicine, 70, 2045 - 2051.

McConnell, D., \& Savage, A. (2015). Stress and resilience among families caring for children with intellectual disability: expanding the research agenda. Current developmental disorders reports, 2(2), 100-109.

Mickelson, K. D. (2001). Perceived stigma, social support, and depression. Personality and Social Psychology Bulletin, 27 (8), 1046 - 1056.

Mikami, A. Y., Chong, G. K., Saporito, J. M. \& Na, J. J. (2015). Implications of parental affiliate stigma in families of children with ADHD. Journal of Clinical Child \& Adolescent Psychology, 44 (4), $595-603$.

Mitchell, G. E. \& Locke, K. D. (2015). Lay beliefs about autism spectrum disorder among the general public and childcare providers. Autism, 19 (5), $553-561$.

Mitter, N., Ali, A. \& Scior, K. (2018). Stigma experienced by family members of people with intellectual and developmental disabilities: multidimensional construct. BJPsych Open, 4, 332 -338 .

Myers, R. (1990). Classical and Modern Regression With Applications (2nd ed.). Boston, MA: Duxbury.

Myers, B. J., Mackintosh, V. H. \& Goin-Kochel, R. P. (2009). "My greatest joy and my greatest heart ache": Parents' own words on how having a child in the autism spectrum has affected their lives and their families' lives. Research in Autism Spectrum Disorders, 3, 670 - 684.

Nurullah, A. S. (2013). "It’s really a roller coaster": Experience of parenting children with developmental disabilities. Marriage and Family Review, 49, 1 - 34. 
Papadopoulos, C., Lodder, A., Constantinou, G., \& Randhawa, G. (2019). Systematic review of the relationship between autism stigma and informal caregiver mental health. Journal of autism and developmental disorders, 49(4), 1665-1685.

Park, E. R., Perez, G. K., Millstein, R. A., Luberto, C. M., Traeger, L., Proszynski, J., ... \& Kuhlthau, K. A. (2020). A Virtual Resiliency Intervention Promoting Resiliency for Parents of Children with Learning and Attentional Disabilities: A Randomized Pilot Trial. Maternal and child health journal, 24(1), 39-53.

Peer, J. W. \& Hillman, S. B. (2014). Stress and resilience for parents pf children with intellectual and developmental disabilities: A review of key factors and recommendations for practitioners. Journal of Policy and Practice in Intellectual Disabilities, 11 (2), 92 - 98.

Peters, K. \& Jackson, D. (2009). Mothers' experiences of parenting a child with attention deficit hyperactivity disorder. Journal of Advanced Nursing, 65 (1), $62-71$.

Pit-ten Cate, I.M. (2003). Family Adjustment to Disability and Chronic Illness in Children, Doctoral Dissertation. University of Southampton, UK.

Rutter, M. (1987). Psychosocial resilience and protective mechanisms. American Journal of Orthopsychiatry, 57 (3), $316-331$.

Shin, J., Nhan, N. V., Crittenden, K. S., Hong, H. T. D., Flory, M. \& Ladinsky, J. (2006). Parenting stress of mothers and fathers of young children with cognitive delays in Vietnam. Journal of Intellectual Disability Research, 50 (10), 748 - 760.

Sinclair, V. G., \& Wallston, K.A. (2004). The development and psychometric evaluation of the Brief Resilient Coping Scale. Assessment, 11 (1), 94 - 101.

Weisner, T. S., Matheson, C., Coots, J., \& Bernheimer, L. P. (2005). Sustainability of daily routines as a family outcome. In Learning in cultural context (pp. 41-73). Springer, Boston, MA. 
Werner, S. \& Shulman, C. (2013). Subjective well-being among family caregivers of individuals with developmental disabilities: The role of affiliate stigma and psychosocial moderating variables. Research in Developmental Disabilities, 34, 4103 - 4114.

Werner, S. \& Shulman, C. (2015). Does type of disability make a difference in affiliate stigma among family caregivers of individuals with autism, intellectual disability or physical disability?. Journal of Intellectual Disability Research, 59 (3), 272 - 283.

Zimet, G. D., Dahlem, N. W., Zimet, S. G. \& Farley, G. K. (1988). The Multidimensional Scale of Perceived Social Support. Journal of Personality Assessment, 52, 30 - 41. 